\title{
Agricultura urbana e Segurança Alimentar: estudo no município de Santa Maria - RS
}

\author{
Cristiane Cardoso Pessoa ${ }^{1}$, Marcelino de Souza ${ }^{2}$ e Ilaine Schuch ${ }^{3}$
}

\begin{abstract}
No contexto da nova relação do rural e urbano, a agricultura urbana ganha importância em função de aspectos a ela ligados, tais como a crescente urbanização, a pobreza, problemas de abastecimento e valores fora de mercado. Todavia, os estudos existentes no Brasil sobre a temática ainda são escassos. O objetivo principal deste trabalho é apresentar os resultados de uma investigação sobre a contribuição da agricultura urbana na melhoria da renda e da alimentação de famílias pobres. Para tal, foram entrevistadas, inicialmente, 38 e, posteriormente, 20 famílias, em cinco bairros do município de Santa MariaRS. Os resultados revelam que a atividade não cumpre necessariamente o papel de provedora de renda adicional, mas conduz a uma economia expressiva, pois certos alimentos deixam de ser comprados. A produção obtida oferece nutrientes importantes, ficando ausentes os alimentos mais ricos em minerais, os quais não são produzidos pelas famílias. A atividade pode ser considerada um modo de produção fora de mercado ou uma economia de subsistência e cumpre papel relevante na complementação da alimentação, fornecendo produtos frescos e relativamente livres de contaminantes industriais, o que contribui para a segurança alimentar e nutricional das famílias.
\end{abstract}

Palavras-chave: agricultura urbana, pobreza e segurança alimentar.

\section{Urban agriculture and food security: study in the city of Santa Maria - RS}

In the context of the new rural and urban relationships, the urban agriculture acquires special importance due to aspects such as the growing urbanization, poverty, supply problems and the occurrence of non-market values. In spite of this perspective, Brazilian studies in this area are rather scarce. The main goal of this work was to investigate the contribution of urban agriculture to the income and food supply of poor urban families. To do so, a sample of 38 (later 20) families were initially interviewed, from five districts of the city of Santa Maria - RS. The results showed that the activity did not necessarily fulfill the role of an additional income provider, but lead to a significant economy, because certain foods were no longer bought. The home-grown produce provided the family members with important nutrients, although mineral-rich foods were not produced by the families. Although urban agriculture can be considered as an out-of-market activity or a subsistence economy, it has an important role in the complementation of the food supply, providing fresh and nutritious food items, which quite free of industrial contaminants, thus contributing to the food security and safety of urban families.

Keywords: urban agriculture, poverty and food security.

${ }^{1}$ Professora Substituta do Departamento de Educação Agrícola e Extensão Rural e mestranda do Curso de Pós-Graduação em Extensão Rural da Universidade Federal de Santa Maria (UFSM). Endereço: Rua Benjamim Constant, 860. Apto. 205. Centro Santa Maria-RS. CEP: 97050-021. E-mail: cricap@mail.ufsm.br

${ }^{2}$ Professor Adjunto do Departamento de Educação Agrícola e Extensão Rural da Universidade Federal de Santa Maria (UFSM). Endereço: Rua Venâncio Aires, 523. Apto. 504. Centro. Santa Maria - RS. CEP: 97.010-001 E-mail: marcelino.souza@uol.com.br

${ }^{3}$ Professora Assistente do Departamento de Medicina Social da Universidade Federal do Rio Grande do Sul (UFRGS). Endereço: Rua Henrique Dias, 194 apartamento 303. Bom Fim, Porto Alegre - RS. CEP: 90035-100. E-mail: ischuch@uol.com.br 


\section{Introdução}

No Brasil, nos últimos 50 anos e, principalmente a partir de 1980, houve uma crescente urbanização, seguindo a tendência mundial. Esse fenômeno provocou uma forte redução da população rural em todas as regiões. Mesmo nas décadas posteriores à de 80, o êxodo rural continuou sendo uma realidade, o que conduziu o país a taxas crescentes de população urbana, mesmo que distintamente nas diversas regiões do país (CAMARANO \& ABRAMOVAY, 1999).

Esse crescimento resulta em um impacto, conduzindo a "uma importante mudança nos vetores de expansão física das cidades, fazendo com que atividades consideradas como essencialmente agrícolas, no passado, passem a ter expressão econômica nos espaços urbanos" (PEREIRA, 2000, p.2).

Nesse sentido, a agricultura cruzou as fronteiras entre a dimensão econômica, ecológica, política e cultural, adquirindo um caráter multifuncional ${ }^{4}$. Nesse contexto, surge a agricultura no meio urbano, e esta, quando praticada de modo apropriado, poderá, segundo o Comitê de Agricultura (COAG, 1999), aumentar a quantidade de alimentos disponíveis, melhorar a segurança alimentar em épocas de crise ou grave escassez de alimentos, melhorar o grau de frescor de alimentos perecíveis e, ainda, oferecer oportunidades de empregos produtivos num setor em que os obstáculos ao ingresso são de pouca importância.

Em vista desses acontecimentos, em todo o mundo, notadamente nos países menos desenvolvidos, tem sido detectado um fenômeno em que um crescente número de residentes urbanos se dedica às atividades agrícolas ${ }^{5}$. Essas atividades agrícolas têm sido comumente chamadas de agricultura urbana. Fleury \& Donadieu (1997) sugerem empregar esse termo para designar os sistemas agrícolas das periferias urbanas orientados para as novas necessidades urbanas, mesmo ressaltando que a expressão possui mais de um significado, podendo ser empregada em diferentes situações ou para distintos grupos de profissionais. Seja qual for a interpretação dada para "agricultura urbana", dependendo do autor e do país no qual se insere, o termo, indiscutivelmente, está relacionado com a autosuficiência alimentar das cidades.

Outro aspecto importante é mencionado por Zeeuw et al. (2000) ao destacarem que as análises das tendências atuais dos sistemas de alimentação dos pobres urbanos mostram que, para garantir sua segurança alimentar, é necessária a combinação da produção de alimentos nas zonas rurais e urbanas.

\section{A Food and Agriculture Organization - FAO} (1996) também ressalta que a agricultura urbana pode constituir-se em uma importante contribuição na questão alimentar e até para o aumento da renda da população em muitas cidades do mundo em desenvolvimento. No entanto, a organização salienta que ela fornece não somente benefícios de ordem econômica, mas também de recreação, lazer e ecológicos aos citadinos.

Em relação aos tipos dos agricultores urbanos, a maioria, segundo registros da United Nations Development Programme - UNDP (1996), tem origem nos grupos de baixa renda, em muitos países em desenvolvimento.

Além disso, freqüentemente, eles cultivam terras que não possuem. Entretanto, em alguns países (incluindo Argentina e Estados Unidos), agricultores de renda média, que são a maioria, praticam primariamente cultivo de "quintal". A diferença entre as práticas agrícolas dos agricultores de baixa renda e daqueles de renda elevada não está apenas no tamanho das terras, mas nos sistemas de produção e produtos. Enquanto a monocultura é comum entre agricultores abastados, os agricultores de baixa renda tendem a escolher sistemas de produção agrícola diversificados, que requerem baixo capital e minimizam riscos (UNDP, 1996).

Zeeuw et al. (2000) salientam também que a agricultura urbana é uma atividade que exige políticas públicas para sua implementação, principalmente no que diz respeito às políticas de uso de solos, saúde,

\footnotetext{
${ }^{4}$ A multifuncionalidade define-se como "um conjunto das contribuições da agricultura a um desenvolvimento econômico e social considerado em sua unidade; o reconhecimento oficial da multifuncionalidade exprime a vontade com que essas diferentes contribuições podem ser associadas duravelmente, de modo coerente, segundo as modalidades julgadas satisfatórias pelos cidadãos". (BLANCHEMANCHE et al., 2000, p.42).

${ }^{5}$ Esse crescimento tem sido relatado principalmente nas pesquisas realizadas nos países africanos. A título de exemplo, ver DrakakisSmith, D. et al. (1995), entre outros estudos.
} 
ambientais e de desenvolvimento social. Por isso, é essencial o conhecimento das características específicas dos locais e as diferentes finalidades da agricultura urbana para que sejam formuladas políticas adequadas de intervenção.

Em quase todo o mundo se encontram pesquisas explorando a temática da agricultura urbana. $\mathrm{O}$ trabalho pioneiro de pesquisa em agricultura urbana realizado no Brasil é o de Frère et al. (1999), o qual apresenta os resultados de uma investigação realizada em Belém-PA, com o objetivo de conhecer os tipos e dimensionar a agricultura naquele município.

Este artigo tem como objetivo apresentar os resultados de uma investigação sobre a contribuição da agricultura urbana na melhoria da renda e da alimentação de famílias pobres ${ }^{6}$. Especificamente, a pesquisa se propôs a conhecer os agricultores urbanos e a atividade; averiguar os produtos obtidos, a forma de produção e o destino dos produtos e identificar a contribuição econômica e de segurança alimentar da atividade.

\section{Metodologia}

Esta pesquisa teve início com a tentativa de identificação do fenômeno da agricultura urbana no município de Santa Maria, Estado do Rio Grande do Sul. O município situa-se na região central do Estado. Segundo o Censo IBGE (2000), a população urbana é de 230.468 habitantes e a rural, de 12.928 habitantes, respectivamente $94,7 \%$ e $5,3 \%$ da população total. Esses dados permitem concluir que Santa Maria é um município nitidamente urbano, segundo os critérios do IBGE. Esta foi uma das razões pelas quais o município foi escolhido para a realização da pesquisa.

No perímetro urbano de Santa Maria, foram identificadas as comunidades que integram os bolsões de miséria ${ }^{7}$ da cidade. A intenção era estudar a agricultura urbana no contexto da pobreza. As comunidades foram escolhidas intencionalmente em localidades situadas em distintas zonas do município, sendo elas Vila Arco-íris, Vila Lídia, Urlândia, Renascença, Vila Lorenzi, Nossa Senhora do Trabalho, Aparício de Moraes e Montanha Russa. Todas essas comunidades foram visitadas para fins de coleta de dados durante o mês de fevereiro até a primeira quinzena de março de 2004, pela própria pesquisadora, tendo sido coletados dados de 38 famílias.

Para a definição do número de famílias a serem pesquisadas nas comunidades, utilizou-se uma amostragem não-probabilística, autogerada. Nela, o tamanho e a localização da população não são conhecidos a priori pelo pesquisador; então, a amostragem é composta à medida que o pesquisador identifica um elemento e solicita-lhe que indique conhecidos que também façam parte da população em estudo, e assim sucessivamente; dessa forma a amostra é construída (MATTAR, 1997).

O instrumento utilizado para o levantamento das informações foi o questionário. Esse questionário possuía 32 questões fechadas, algumas com subdivisões, e 1 questão aberta. Tratavam tanto de características familiares como das estruturais e agrícolas, e foi aplicado aos responsáveis que previamente declararam possuir atividades agrícolas.

Os dados coletados nos questionários foram digitados em planilhas do programa Excel, constituindo um banco de dados. Posteriormente, esses dados foram importados pelo programa estatístico SPSS (Statistical Product and Service Solutions), sendo este utilizado para o cruzamento das variáveis selecionadas e de interesse do estudo.

Numa segunda fase do trabalho, foi realizada uma nova pesquisa de campo, em uma subamostra de

\footnotetext{
${ }^{6}$ Zaluar (1994, p. 33) define os pobres, de um ponto de vista meramente descritivo, como "todos aqueles que estão incluídos nas faixas de renda mais baixas (até 3 a 5 salários mínimos) ou os que exercem as atividades mais mal remuneradas na economia nacional. Entre eles estão obviamente os operários e assalariados do terciário semi ou não qualificados e que recebem baixos salários em virtude da política salarial vigente, bem como os trabalhadores por conta-própria pouco ou não especializados, quer sejam estabelecidos ou não".

${ }^{7}$ Esses bolsões foram identificados pela Rede de Solidariedade e divulgados através de documento intitulado "Projeto Institucional de Extensão: Núcleo da UFSM em apoio à Rede de Solidariedade” (abril de 2003).
} 
20 famílias, com o objetivo de levantar dados acerca do consumo alimentar familiar. Para tal, utilizou-se a metodologia desenvolvida por Galeazzi et al. (1996), com a finalidade de fazer o inquérito de consumo familiar, sendo este um questionário padronizado com uma lista de alimentos, em que foram registrados aqueles consumidos durante o mês imediatamente anterior ao dia de coleta.

Foram elaborados cálculos relativos ao consumo médio per capita de energia e nutrientes selecionados. Também foi considerado o fator de correção dos alimentos para a obtenção da quantidade comestível (LUNA, 1995). Por meio do software Virtual Nutri (PHILIPPI, S. T; SZARFARC, S. C.; LARRWRZA, A. R., 1996) foram elaborados os cálculos relativos à composição energética e nutricional da alimentação das famílias.

Nesta pesquisa foram adotados parâmetros da FAO/OMS/ONU (1985) e da RDA (1989) para estabelecer as recomendações médias preconizadas de energia $(2.261,8 \mathrm{kcal} / \mathrm{dia})$ e de proteína $(51 \mathrm{~g} / \mathrm{dia})$, calculadas a partir da informação de idade e sexo de cada membro da família. No caso das vitaminas e sais minerais, foram utilizados os valores registrados na publicação Dietary Reference Intakes-DRIs (2002), para efeitos de comparações entre o consumo médio per capita e a recomendação média preconizada, a saber: vitamina A $(867 \mathrm{mcg} / \mathrm{dia})$, vitamina C $(77 \mathrm{mg} / \mathrm{dia})$, cálcio $(1.115 \mathrm{mg})$ e ferro $(11,6 \mathrm{mg} / \mathrm{dia})$.

\section{Resultados e Discussão}

\section{Breve caracterização da população pesquisada}

As tabelas apresentadas a seguir mostram alguns dos principais resultados obtidos através da aplicação dos questionários às famílias, visando obter informações pertinentes a este trabalho. $\mathrm{Na}$ Tabela 1, pode-se verificar a distribuição das famílias de acordo com o número de pessoas nas localidades pesquisadas.

O total representa o número de famílias que foram entrevistadas em cada local, e o número de pessoas diz respeito ao tamanho das famílias. A maior parte das famílias é formada por duas e quatro pessoas, sendo que apenas duas famílias, uma na Vila Urlândia e outra na Renascença, apresentaram sete indivíduos na família, residindo no domicílio visitado. No geral, pode-se verificar que não são famílias numerosas. De acordo com o IBGE (Censo, 2000), esse fato se explica pela queda acelerada da fecundidade, ocorrida no país nas últimas duas décadas, conduzindo a uma redução no tamanho das famílias. O número médio de membros das famílias caiu de 3,9 pessoas, em 1991, para 3,5 em 2000. As famílias com um a quatro componentes estão mais presentes nas áreas urbanas, enquanto que as famílias com cinco a onze pessoas são mais freqüentes nas áreas rurais.

$\mathrm{Na}$ Tabela 2, têm-se os resultados relativos ao sexo das pessoas ocupadas na agricultura urbana.

TABELA 1. Número de pessoas nas famílias, segundo as localidades pesquisadas.

\begin{tabular}{|c|c|c|c|c|c|c|c|}
\hline \multirow[t]{2}{*}{ Localidades } & \multicolumn{6}{|c|}{ Número de pessoas na família } & \multirow[t]{2}{*}{ Total } \\
\hline & 1 & 2 & 3 & 4 & 5 & 7 & \\
\hline Urlândia & & 4 & 9 & 4 & 1 & 1 & 19 \\
\hline Renascença & & & 1 & 2 & & 1 & 4 \\
\hline Vila Lorenzi & 2 & 2 & & 3 & 1 & & 8 \\
\hline Aparício de Moraes & & 1 & 2 & & 1 & & 4 \\
\hline Montanha Russa & & 1 & 2 & & & & 3 \\
\hline TOTAL & 2 & 8 & 14 & 9 & 3 & 2 & 38 \\
\hline
\end{tabular}


TABELA 2. Sexo das pessoas ocupadas na agricultura

\begin{tabular}{llll}
\hline Agricultores & \multicolumn{2}{c}{ Sexo } & Total \\
\cline { 2 - 3 } Urbanos & Masculino & Feminino & \\
\hline Número de pessoas & $30(52,6 \%)$ & $27(47,3 \%)$ & $57(100 \%)$
\end{tabular}

Verifica-se que há pouca diferença entre homens e mulheres que trabalham nas produções agrícolas urbanas, sendo que, do total de 57 pessoas nas famílias, 30 são do sexo masculino e 27 do sexo feminino. No trabalho de Nugent (2000), os resultados mostram que as mulheres estão muito mais envolvidas nessa atividade, e os homens têm mais chance de se vincularem à produção para o mercado, nos casos em que as mulheres estão muito ocupadas com outras tarefas. Nessas comunidades, não se pode afirmar que existe predominância de um dos sexos no trabalho da agricultura urbana, ao contrário do que se pode encontrar na literatura ${ }^{8}$, em que se ressalta que a maior parte dos agricultores urbanos são mulheres.

A Tabela 3 apresenta os estratos de idade das pessoas envolvidas com o trabalho na agricultura urbana.

Entre as 57 pessoas que praticam a atividade, a maioria encontra-se na faixa etária de 41 até 59 anos, e, somadas às pessoas que possuem mais de 60 anos, pode-se concluir que os indivíduos que aderem à agricultura urbana nessas comunidades não são exatamente os mais jovens, mas sim, aqueles com idade superior a 40 anos.

$\mathrm{Na}$ Tabela 4, pode-se verificar o local de origem dos agricultores urbanos pesquisados. Desse total, constata-se que cerca de 37\% são oriundos da zona rural de outras cidades e $26,3 \%$, da zona rural de Santa Maria, ou seja, 63\% do total das pessoas que praticam agricultura urbana são de origem rural. Isso remete à questão do êxodo rural, que conduz essas pessoas para a cidade, com o objetivo de melhorar as condições de vida, e ainda a tradição na agricultura que elas trazem, como é detalhado no trabalho de COSTA BEBER (1998).

Existe uma parte das pessoas, aproximadamente $37 \%$, que é de origem urbana, e pode ter outras razões para a prática da agricultura, como a própria subsistência, já que é integrante de comunidades pobres. Outras razões dizem respeito ao lazer que a atividade lhes pode proporcionar. A esse respeito, Altieri et al. (1999) salientam que a agricultura urbana, para as pessoas nascidas na cidade, se constitui numa oportunidade para aprender e apreciar o processo de cultivo. Para os recém-migrantes da zona rural, a atividade representa uma forma de utilizar suas especialidades agrícolas e, para alguns, um refúgio onde eles podem trabalhar novamente, mas de forma diferente, com a terra e religados à natureza.

Na Tabela 5, estão contabilizadas as ocupações das pessoas que trabalham na agricultura urbana. Inicialmente, cabe destacar que, do total de 57 pessoas que inicialmente declararam dedicação à prática da agricultura urbana, nem todas podem ser consideradas "pessoas ativas", pois no grupamento estão incluídos aposentados, pensionistas e

TABELA 3. Estratos de idade das pessoas envolvidas na agricultura urbana.

\begin{tabular}{lcccccc}
\hline $\begin{array}{l}\text { Agricultores } \\
\text { Urbanos }\end{array}$ & \multicolumn{5}{c}{ Estratos de idade } & Total \\
\cline { 2 - 5 } & Até 14 anos & 15 até 22 anos & 23 até 40 anos & 41 até 59 anos & 60 anos e mais & \\
\hline № de pessoas & $1(1,75 \%)$ & $1(1,75 \%)$ & $12(21 \%)$ & $31(54,3 \%)$ & $12(21 \%)$ & $\mathbf{5 7}$ \\
\hline
\end{tabular}

TABELA 4. Local de origem das pessoas que trabalham na agricultura urbana.

\begin{tabular}{|c|c|c|c|c|c|}
\hline \multirow{2}{*}{$\begin{array}{l}\text { Agricultores } \\
\text { Urbanos }\end{array}$} & \multicolumn{4}{|c|}{ Local de Origem } & \multirow[t]{2}{*}{ Total } \\
\hline & S. Maria (urbana) & S. (rural) & Outras cidades (urbana) & Outras cidades (rural) & \\
\hline $\mathrm{N}^{\circ}$ de pessoas & $15(26,3 \%)$ & $15(26,3 \%)$ & $6(10,5 \%)$ & $21(36,8 \%)$ & $57(100 \%)$ \\
\hline
\end{tabular}

\footnotetext{
${ }^{8}$ No livro Urban Agriculture: Food, Jobs and Sustainable Cities (UNDP, 1996), existe a informação de que, em muitos locais do mundo, as mulheres têm maior participação na agricultura urbana do que os homens.
} 
TABELA 5. Grupos de ocupações das pessoas ativas que trabalham na agricultura urbana.

\begin{tabular}{lccc}
\hline Grupos de ocupação & Número de pessoas & \% Acumulada & \% \\
\hline Administração pública & 1 & 4 & 4 \\
Professores e outros da educação & 1 & 4 & 12 \\
Agricultor por conta própria & 1 & 32 & 44 \\
Serviços da construção civil & 8 & 8 & 52 \\
Ocupações agroindustriais & 2 & 4 & 56 \\
Indústria de transformação & 1 & 12 & 68 \\
Comércio não-especificado & 3 & 4 & 72 \\
Motoristas & 1 & 16 & 88 \\
Serviços domésticos remunerados & 4 & 8 \\
Serviços pessoais não-domésticos & 2 & 4 \\
Outros serv. pessoais não-domésticos & 1 & $\mathbf{4}$ & 100 \\
\hline TÓTAL & $\mathbf{2 5}$ & $\mathbf{1 0 0}$ & - \\
\hline
\end{tabular}

mulheres com atividades domésticas 9 . Descontando essas pessoas, chega-se ao número de 25 pessoas ativas que se dedicam também à agricultura urbana. Estas se encontram ocupadas nos serviços de construção civil (pedreiros e pintores), outras em serviços domésticos (preferencialmente as mulheres), e ainda há aquelas classificadas como vendedores informais e prestadores de serviço por conta própria.

A predominância de pessoas que se ocupam em serviços da construção civil é um fato que pode ser associado, talvez, ao caráter precário dessa ocupação, na forma de subemprego. As demais ocupações declaradas mostram um aspecto importante: as baixas qualificações e rendimentos desses trabalhos e sua conseqüente precariedade.

Na Tabela 6, é apresentada a distribuição das famílias pesquisadas segundo os estratos de renda per capita. Se for adotada a "linha da pobreza" como sendo igual a $\mathrm{R} \$ 120,00$, observa-se, na Tabela 6, que 21,1\% das famílias possuem rendimentos que as classificam abaixo da linha de pobreza ${ }^{10}$. A renda média per capita é somente de $\mathrm{R} \$ 252,77$, e a renda mediana per capita atinge apenas $\mathrm{R} \$ 218,00$. Se observarmos atentamente essas informações apresentadas na Tabela 6 , pode-se verificar que menos de $1 / 4$ das famílias pesquisadas possuem renda que as situa abaixo da chamada "linha de pobreza".

Esse curioso resultado permite levantar a hipótese de que, embora a pesquisa tenha sido realizada no contexto da pobreza, os praticantes da agricultura urbana não apresentam rendimentos que os classifiquem entre as famílias relativamente mais pobres. Uma outra razão que pode ser aventada é a existência de aposentados e pensionistas entre os membros das famílias, o que permite uma elevação e

\footnotetext{
${ }^{9}$ Segundo a classificação das Pesquisas Nacionais de Amostras de Domicílios - PNADs, anteriores a 1992, do Instituto Brasileiro de Geografia e Estatística (IBGE), somente são consideradas “pessoas ativas ou ocupadas” aquelas com 10 anos e mais que trabalhavam 15 horas ou mais na semana de referência da pesquisa. Adotou-se esse conceito como critério de separação das pessoas ativas neste artigo. Com a aplicação desse conceito, restaram somente 47 pessoas, em relação às 57 inicialmente apresentadas nas Tabelas 2 , 3 e 4 . Se se levar em conta somente as que declararam praticar agricultura urbana, restarão apenas 25 pessoas ativas, que são apresentadas na Tabela 5. ${ }^{10} \mathrm{O}$ valor do salário mínimo nacional no período da pesquisa era de $\mathrm{R} \$ 240,00$. Segundo Rocha (1996, p. 3), "é consensualmente aceito que a variável de renda mais adequada para confronto com a linha de pobreza é a renda familiar per capita, que leva em consideração todos os rendimentos das pessoas do núcleo familiar, o número de pessoas e o papel da família como unidade solidária de consumo e rendimento". A metodologia oficial usa como referência o salário mínimo, isto é $1 \frac{1}{2}$ do salário mínimo familiar per capita, limite abaixo do qual se define uma família pobre. Definição encontrada no site do IBGE (http://www.ibge.gov.br/ibgeteen/glossario/pobreza. html. 1 set. 2005).
} 
TABELA 6. Distribuição das famílias, segundo os estratos de renda per capita.

\begin{tabular}{lccc}
\hline Estratos de Renda (em Reais) & Número & $\%$ Acumulada & $\%$ \\
\hline 60 até 120 & 8 & 21,1 & 21,1 \\
125 até 240 & 15 & 39,5 & 60,5 \\
250 até 370 & 9 & 23,7 & 84,2 \\
393,33 até 456,66 & 4 & 10,5 & 94,7 \\
700 e mais & 2 & 5,3 & 100,0 \\
\hline TOTAL & 38 & $\mathbf{3 0 0}$ & - \\
\hline
\end{tabular}

estabilização das rendas.

\section{A prática da agricultura urbana}

$\mathrm{Na}$ Tabela 7, são apresentados os resultados relativos ao tempo de prática da agricultura urbana pelas familias. Por meio das informações, verificou-se que a agricultura urbana é, na maioria dos casos, uma atividade relativamente tradicional entre as familias, pois é praticada há mais de cinco anos, em mais de 60\% dos casos.

TABELA 7. Tempo de prática da agricultura urbana, segundo as famílias pesquisadas.

\begin{tabular}{lcc}
\hline Tempo (anos) & Número & $\%$ \\
\hline Menos de 1 ano & 4 & 10,5 \\
Entre 1 e 2 anos & 4 & 10,5 \\
Entre 2 e 5 anos & 7 & 18,4 \\
Mais de 5 anos & 23 & 60,5 \\
\hline TOTAL & $\mathbf{3 8}$ & $\mathbf{1 0 0 , 0}$ \\
\hline
\end{tabular}

Considerando as produções mais recentes, entre o período de menos de 1 ano até 2 anos, apenas 21,1\% das famílias aparece nessa situação. Com base nesses resultados, pode-se inferir que a agricultura urbana parece não se constituir em uma prática transitória. Ela não se derivaria apenas da crise econômica, mas se constituiria em uma prática permanente das familias e mereceria ser estimulada pelos órgãos públicos. Contudo, há necessidade de se manter a continuidade das pesquisas para poder (ou não) fazer a afirmação de forma categórica.

A Tabela 8 apresenta os locais onde os agricultores desenvolvem a atividade. Nela, pode-se verificar que a característica da agricultura urbana praticada é aquela das hortas nos quintais das casas ou, em alguns casos, terrenos próximos, já que 78,9\% dos agricultores urbanos utilizam seus quintais como espaço para produção. Em 21,1\% dos casos, a produção ocorre em terrenos privados, dos próprios entrevistados.

TABELA 8. Locais de produção da agricultura urbana.

\begin{tabular}{lcc}
\hline Local & Número & $\%$ \\
\hline Quintal de casa & 30 & 78,9 \\
Terrenos privados & 8 & 21,1 \\
\hline TOTAL & $\mathbf{3 8}$ & $\mathbf{1 0 0 , 0}$ \\
\hline
\end{tabular}

Os principais produtos encontrados na pesquisa estão descritos na Tabela 9. Pode-se observar que existe ampla variedade, sendo incluídos nos cultivos desde hortaliças e temperos, legumes, frutas e grãos. As hortaliças aparecem em maior quantidade e em variedade.

Os destinos dados para os produtos obtidos pelas famílias de agricultores urbanos estão apresentados na Tabela 10. Como a questão admitia mais de uma resposta, tem-se que $100 \%$ das familias de agricultores consomem os alimentos que produzem. Desse total, 15,8\% das famílias também declararam que, além de consumir, também comercializam parte de sua produção, e ainda 23,7\% consomem e doam, normalmente a vizinhos, ou trocam com estes o excedente da produção.

Na Tabela 10, é visível que a principal contribuição da agricultura urbana para essas populações é a nutricional, na medida em que complementam sua alimentação com o que plantam, e apenas em alguns casos comercializam os produtos visando ao lucro.

Tomando como referência a descrição de Sachs (2004), o qual identifica os modos de produção na economia e seus circuitos, a agricultura urbana 
TABELA 9. Principais alimentos produzidos pelos agricultores urbanos.

\begin{tabular}{|c|c|}
\hline Produto & $\%$ \\
\hline Couve & 84,2 \\
\hline Alface & 65,8 \\
\hline Radiche & 63,2 \\
\hline Feijão & 57,9 \\
\hline Salsa & 52,6 \\
\hline Cebolinha & 52,6 \\
\hline Rúcula & 44,7 \\
\hline Milho & 42,0 \\
\hline Beterraba & 39,5 \\
\hline Tomate & 36,8 \\
\hline Laranja & 36,8 \\
\hline Bergamota & 31,6 \\
\hline Mamão & 28,9 \\
\hline Abóbora & 26,3 \\
\hline Pimentão & 23,7 \\
\hline Goiaba & 23,7 \\
\hline Limão & 23,7 \\
\hline Cenoura & 21,0 \\
\hline Mandioca & 21,0 \\
\hline Maracujá & 13,1 \\
\hline
\end{tabular}

TABELA 10. Destino dos produtos obtidos pelas famílias de agricultores urbanos.

\begin{tabular}{lc}
\hline Destino & Número \\
\hline Consumo & 38 \\
Comércio & 6 \\
Trocas/doações & 9 \\
\hline
\end{tabular}

TABELA 11. Principais razões citadas para a prática da agricultura urbana.

\begin{tabular}{lcc}
\hline Razões & Número & $\%$ \\
\hline Para consumo e subsistência & 28 & 73,7 \\
Já possuem tradição com agricultura & 17 & 44,7 \\
Praticam por lazer & 10 & 26,3 \\
Para aumentar a renda da família & 2 & 5,3 \\
\hline TOTAL & $\mathbf{5 7}$ & - \\
\hline
\end{tabular}

poderia ser classificada como modo de produção fora do mercado, pelas suas características domésticas e de autoconsumo.

A Tabela 11 traz as razões citadas pelos agricultores urbanos para praticarem a agricultura urbana. Nessa questão, mais de uma alternativa podia ser escolhida.

Entre as principais razões declaradas, 28 delas referiram-se à prática da agricultura urbana para consumir os produtos e auxiliar na subsistência. Também se pode verificar que 17 famílias responderam que possuíam tradição com a agricultura e por isso continuaram a cultivar.

O trabalho de Nugent (2000) mostra que as razões que dão origem à agricultura urbana são variadas, mas encontram-se entre elas, principalmente, a subsistência e a geração de renda, dependendo das condições de vida existentes nas várias cidades. Para o grupo de menor renda pesquisado, fica claro que a importância dos cultivos reside basicamente no aspecto relativo à alimentação das famílias.

$\mathrm{Na}$ Tabela 12, são apresentados os resultados relativos aos insumos utilizados nas produções agrícolas urbanas. Pode-se verificar que a agricultura urbana, praticada por esses grupos mais pobres, é bastante "limpa", no sentido da reduzida utilização de produtos químicos e agrotóxicos.

A maioria dos produtores compra suas sementes provavelmente devido à dificuldade de produção própria delas. $\mathrm{O}$ esterco de animais é um produto muito utilizado na adubação, e verifica-se que em apenas três casos foi declarada a utilização de algum tipo de adubo químico para a produção. E, ainda, 18,4\% não utilizam nada no solo para melhorar o cultivo, acreditando não haver necessidade. Os métodos de controle das pragas também são bastante naturais, pois 60,5\% dos produtores fazem uso de tratamentos orgânicos, como cinzas em cima das folhas, calda de fumo e algumas ervas secas. Outros 23,7\% utilizam métodos de controle manuais, e apenas em quatro casos, ou 10,8\%, tratam as pragas com agrotóxicos. Duas famílias declararam não utilizar nada, pois não são expressivas suas perdas com pragas, ou quase nunca estas ocorrem. Poder-se-ia inferir que essas produções utilizam práticas muito semelhantes às agroecológicas. Esse fato pode derivar- 
TABELA 12. Tipos de insumos utilizados nas produções agrícolas urbanas.

\begin{tabular}{|c|c|c|c|}
\hline Tipos de Insumos & & Número & $\%$ \\
\hline \multirow[t]{3}{*}{ Sementes } & Próprias & 7 & 18,4 \\
\hline & Compradas & 31 & 81,6 \\
\hline & TOTAL & 38 & 100,0 \\
\hline \multirow[t]{4}{*}{ Tipo de adubo } & Esterco orgânico & 28 & 73,7 \\
\hline & Adubo químico & 3 & 7,9 \\
\hline & Não usam nada & 7 & 18,4 \\
\hline & TOTAL & 38 & 100,0 \\
\hline \multirow[t]{5}{*}{ Métodos de controle de pragas } & Insumos químicos & 4 & 10,8 \\
\hline & Tratamentos orgânicos & 23 & 60,5 \\
\hline & Métodos manuais & 9 & 23,7 \\
\hline & Nada & 2 & 5,0 \\
\hline & TOTAL & 38 & 100,0 \\
\hline
\end{tabular}

se de duas razões: primeiro, as pessoas produzem para autoconsumo, com a intenção da obtenção de alimentos de melhor qualidade; segundo, consideram a produção pequena e com pouco intuito comercial. Sendo assim, preferem não ousar em investimentos com insumos mais caros ${ }^{11}$.

A Tabela 13 traz as informações acerca das principais dificuldades enfrentadas pelas famílias pesquisadas na prática da agricultura urbana.

Nela, pode-se constatar que uma das principais dificuldades citadas pelos agricultores urbanos é a falta de dinheiro, já que as famílias alegam que é necessário investir na atividade para aproveitar ao máximo e da melhor forma possível os espaços existentes. A escassez de dinheiro para investir na agricultura urbana poderia ser minimizada com a possibilidade de acesso dessas famílias ao microcrédito ${ }^{12}$.

Para Yunus (2000), o principal entrave ao sistema, que atinge as famílias pobres, é a falta de acesso a uma poupança e a um mecanismo de seguro. No entanto, ele ainda poderia ser um caminho viável para a inclusão social de alguns grupos menos favorecidos economicamente. Da mesma forma, a falta de maiores espaços para o cultivo é colocada como um empecilho, e finalmente, a falta de conhecimento técnico. Em relação a este aspecto, caberia aos serviços de extensão fornecer as orientações mais adequadas aos agricultores, respeitando seus espaços e condições financeiras, ou seja, uma assistência técnica diferenciada.

TABELA 13. Principais dificuldades citadas na prática da agricultura urbana.

\begin{tabular}{lc}
\hline Dificuldades & $\%$ \\
\hline Falta de dinheiro & 30,61 \\
Falta de espaço & 28,58 \\
Falta de conhecimento técnico & 20,4 \\
Falta de mão-de-obra & 8,16 \\
Falta de água & 8,16 \\
Falta de tempo & 2,04 \\
Não há dificuldades & 2,04 \\
\hline TOTAL & $\mathbf{1 0 0 , 0}$ \\
\hline
\end{tabular}

\footnotetext{
${ }^{11}$ Esses resultados estão de acordo com aqueles obtidos por Altieri et al. (1999, p. 31), que afirmaram que "a agricultura em Cuba tem sido realizada com base em princípios agroecológicos, os quais eliminam o uso de pesticidas químicos sintéticos e fertilizantes, enfatizando a diversificação, reciclagem e o uso de recursos locais".

12 Yunus (2000) conceitua o microcrédito como um bom instrumento de intervenção financeira, de forma que famílias pobres criam laços sociais informais substituindo o banqueiro. As cadeias de microcrédito citadas pelo autor baseiam-se em responsabilidades, em que o não pagamento implica conseqüências morais dentro da comunidade e na agência de empréstimo.
} 

familiar

\section{A contribuição da agricultura urbana na renda}

Na questão monetária, o consumo de alimentos oriundos da agricultura urbana representa uma importante economia de rendimentos para as famílias. A Tabela 14 apresenta a distribuição das famílias em estratos de percentuais de economia obtida com o autoconsumo, em relação à renda total. Essas informações foram calculadas a partir do dado declarado pelas famílias pesquisadas em resposta à pergunta "qual a estimativa do montante economizado com a agricultura urbana (em termos de consumo, em relação a renda familiar)?”

Como se pode verificar na Tabela 14, mais de $1 / 3$ das famílias economizam de 10 a $20 \%$ da renda total com a produção agrícola urbana. Também vale destacar que $26,32 \%$ das famílias chegam a economizar mais de $30 \%$ da renda familiar, por meio da agricultura urbana.

É importante salientar que, por serem famílias de baixa renda, uma economia superior a 30\% em alimentação pode significar uma possibilidade de suprir outras necessidades básicas para essa população, o que talvez de outro modo não fosse possível. Todavia, essas são apenas estimativas, pois existe dificuldade de mensuração das rendas oriundas das explorações agrícolas urbanas, dado que muito do que é produzido não passa diretamente nos canais normais de mercado, como já se mostrou anteriormente.

A partir das informações coletadas, é possível evidenciar, na Tabela 15, as principais despesas citadas pelas 38 famílias. Inicialmente, é preciso afirmar que as despesas variam entre $R \$ 119,00$ e $R \$ 830,00$ por mês, incluindo prestações de moradia, água, luz, gás, transporte, medicamentos e alimentação. A média (mensal) das despesas é de $\mathrm{R} \$ 408,00$ por família. É possível constatar também que praticamente $60 \%$ dos gastos dessas famílias pobres são com alimentação, o que se apresenta de acordo com a literatura internacional.

Neste sentido, a agricultura urbana pode diminuir ou contribuir para aliviar os gastos com alimentação dessas famílias. No trabalho de Avilla \& Veenhuisen (2002), relata-se que os alimentos oriundos da produção para autoconsumo representam uma oportunidade importante para a redução desses gastos com alimentação, principalmente para as

TABELA 14. Percentual de economia obtida com autoconsumo, em relação à renda total das famílias.

\begin{tabular}{lcc}
\hline Estratos & Número de famílias & $\%$ \\
\hline Até $10 \%$ da renda total & 5 & 13,16 \\
Mais de $10 \%$ até $20 \%$ & 14 & 36,84 \\
Mais de $20 \%$ até $30 \%$ & 9 & 23,68 \\
Mais de $30 \%$ & 10 & 26,32 \\
\hline TOTAL & $\mathbf{3 8}$ & $\mathbf{1 0 0 , 0 0}$ \\
\hline
\end{tabular}

TABELA 15. Principais despesas das famílias de agricultores urbanos pesquisados.

\begin{tabular}{lcc}
\hline Despesa & Valor em Reais & $\%$ \\
\hline Água & $1.116,00$ & 7,27 \\
Luz & $1.722,00$ & 11,21 \\
Transporte & $1.025,00$ & 6,67 \\
Gás & $1.161,00$ & 7,55 \\
Remédios & $1.275,00$ & 8,3 \\
Alimentação & $9.060,00$ & 59,0 \\
\hline TOTAL & $\mathbf{1 5 . 3 5 9 , 0 0}$ & $\mathbf{1 0 0 , 0}$ \\
\hline
\end{tabular}


Agricultura urbana e segurança alimentar e nutricional, Pessoa et al.

TABELA 16. Distribuição das famílias de acordo com o consumo e a origem dos alimentos.

\begin{tabular}{|c|c|c|c|}
\hline Grupos/Alimentos & Compra & Produção própria & Doação \\
\hline Arroz & 20 & - & \\
\hline Macarrão & 20 & - & - \\
\hline Pão francês & 16 & & \\
\hline Farinha de trigo & 18 & - & - \\
\hline Farinha de milho & 14 & & - \\
\hline Feijão & 11 & 9 & - \\
\hline Batata-inglesa & 19 & 1 & - \\
\hline Mandioca & - & 8 & 2 \\
\hline Carne bovina & 19 & - & - \\
\hline Frango & 19 & & 1 \\
\hline Salsicha & 5 & - & - \\
\hline Lingüiça & 12 & - & - \\
\hline Peixe & 8 & - & 1 \\
\hline Ovos & 18 & 2 & - \\
\hline Leite & 19 & 1 & \\
\hline Queijo & 12 & - & - \\
\hline Alface & 4 & 12 & \\
\hline Couve & 1 & 17 & - \\
\hline Espinafre & 4 & 4 & - \\
\hline Rúcula & - & 9 & \\
\hline Radiche & - & 14 & - \\
\hline Repolho & 11 & 1 & \\
\hline Tomate & 12 & 8 & - \\
\hline Chuchu & 3 & 6 & - \\
\hline Salsa/cebolinha & - & 17 & - \\
\hline Abóbora & 10 & 5 & - \\
\hline Pimentão & 10 & 6 & \\
\hline Cenoura & 9 & 5 & - \\
\hline Beterraba & 3 & 8 & \\
\hline Cebola & 18 & 2 & - \\
\hline Milho-espiga & 2 & 11 & - \\
\hline Açúcar & 20 & - & \\
\hline Chocolates & 14 & - & - \\
\hline Bolacha doce & 18 & 1 & \\
\hline Bolacha salgada & 16 & - & - \\
\hline Banana & 19 & 1 & - \\
\hline Laranja & 6 & 9 & 1 \\
\hline Limão & 3 & 8 & - \\
\hline Mamão & 11 & 4 & \\
\hline Bergamota & 12 & 8 & - \\
\hline Maçã & 19 & 1 & \\
\hline Maracujá & - & 7 & - \\
\hline Goiaba & - & 5 & 1 \\
\hline Refrigerante & 15 & - & - \\
\hline Suco artificial & 13 & - & - \\
\hline Óleo vegetal & 19 & & \\
\hline Margarina & 19 & - & - \\
\hline Maionese & 14 & & \\
\hline Massa de tomate & 18 & - & - \\
\hline
\end{tabular}

NOTA: Os traços (-) significam que os grupos/alimentos não foram citados pelos entrevistados. 
famílias pobres urbanas, que chegam a gastar até $80 \%$ de sua renda com alimentação.

\section{A contribuição da agricultura urbana para a segurança alimentar e nutricional}

As informações acerca do consumo de alimentos entre a subamostra de 20 famílias revelam que 100\% delas consumiram arroz, macarrão, feijão, batatainglesa, ovos e leite, frutas como a maçã, a bergamota e a banana, legumes como a cebola e o tomate, e que, entre as carnes, as mais consumidas são as de gado e a de frango. Percebe-se a expressiva presença de alimentos industrializados, como biscoitos doces e salgados, refrigerantes, sucos artificiais, chocolates, margarina, maionese e massa de tomate, conforme pode ser observado na Tabela 16, a qual apresenta a distribuição das famílias de acordo com o consumo de alimentos e a origem deles, ou seja, se são oriundos de compras, da produção própria ou de doações.

Essas informações revelam a importância do consumo, a partir da produção própria, de alimentos como o feijão, que quase $50 \%$ das famílias obtêm da produção própria, a mandioca, verduras em geral e frutas como a laranja, a bergamota, o maracujá e a goiaba. Dessa forma, pode-se inferir qual a contribuição da agricultura urbana para a segurança alimentar das famílias pesquisadas. Em especial as verduras e frutas da época parecem ser mais consumidas a partir da disponibilidade possível pela prática da agricultura urbana.

A agricultura urbana tem sido apontada por estudiosos como um elemento importante para garantia da segurança alimentar e saúde nas famílias que a praticam. Frère et al. (1999) mostram as principais funções nas quatro tipologias de micro-agricultura urbana em Belém do Pará, sendo a segurança alimentar e a saúde as principais presentes em todas elas. Um estudo antropométrico realizado em Kampala, Uganda, com crianças menores de 5 anos, indica que a agricultura urbana tem uma associação positiva significativa com um melhor estado nutricional das crianças, particularmente no indicador altura para a idade (Maxwell et al., 1998).

A Tabela 17 mostra as informações relativas ao consumo de energia e proteínas entre as famílias pesquisadas.

Observa-se que cinco famílias apresentam um consumo abaixo do esperado e oito famílias apresentam consumo excessivo em termos de energia, o que pode trazer conseqüências à saúde das pessoas.

Hoje as doenças como a anemia ferropriva, hipovitaminose $\mathrm{A}$, osteoporose e outras por deficiência específica de nutrientes, e as doenças crônicas não-transmissíveis, como obesidade, diabetes mellitus e hipertensão arterial, são alvo de investimentos por meio de políticas públicas de saúde, alimentação e nutrição, porque atingem um substancial número de pessoas, independentemente de classe social. Quanto à proteína, a maioria das famílias apresenta consumo (médio) aparentemente excessivo. Esse nutriente considerado essencial para o adequado estado de saúde e nutrição tem sua demanda mais facilmente atendida, em termos quantitativos. Na Tabela 18, são apresentados os dados referentes ao consumo de vitaminas e sais minerais. Com relação às vitaminas, observa-se que tanto para a vitamina A como para a vitamina $\mathrm{C}$ a maioria das famílias revelou consumo médio que se aproxima dos valores preconizados, resultado provavelmente condicionado pela presença expressiva de verduras e legumes observada na

TABELA 17. Distribuição das famílias de acordo com o consumo médio diário de energia e proteína.

\begin{tabular}{|c|c|c|c|c|}
\hline & \multicolumn{2}{|l|}{ Energia } & \multicolumn{2}{|c|}{ Proteínas } \\
\hline & $\begin{array}{l}\text { Consumo médio per capita } \\
\text { de calorias (kcal/dia) }\end{array}$ & Número & $\begin{array}{l}\text { Consumo médio } \\
\text { per capita (g/dia) }\end{array}$ & Número \\
\hline Menos de $80 \%$ & $1.497,01$ & 5 & 31 & 1 \\
\hline De $80 \%$ até menos de $110 \%$ & $2.021,39$ & 7 & 59 & 1 \\
\hline De $110 \%$ a mais & $3.671,00$ & 8 & 100 & 18 \\
\hline TOTAL & $2.396,46$ & 20 & 63,3 & 20 \\
\hline
\end{tabular}


TABELA 18. Distribuição das famílias de acordo com o consumo médio per capita diário de vitaminas e sais minerais selecionados.

\begin{tabular}{|c|c|c|c|c|c|c|c|c|}
\hline & \multicolumn{4}{|c|}{ Vitaminas } & \multicolumn{4}{|c|}{ Sais Minerais } \\
\hline & A & & $\mathrm{C}$ & & Cálcio & & Ferro & \\
\hline & $\begin{array}{c}\text { Consumo } \\
\text { médio per capita } \\
(\mathrm{mcg} / \mathrm{dia})\end{array}$ & $\mathrm{n}$ & $\begin{array}{c}\text { Consumo } \\
\text { médio per capita } \\
\text { (mg/dia) }\end{array}$ & $\mathrm{n}$ & $\begin{array}{c}\text { Consumo } \\
\text { médio per capita } \\
(\mathrm{mg} / \text { dia })\end{array}$ & $\mathrm{n}$ & $\begin{array}{c}\text { Consumo } \\
\text { médio per capita } \\
(\mathrm{mg} / \mathrm{dia})\end{array}$ & $\mathrm{n}$ \\
\hline Menos de $80 \%$ & - & - & - & - & 393 & 7 & 5,2 & 5 \\
\hline $\begin{array}{l}\text { De } 80 \% \text { até } \\
\text { menos de } 110 \%\end{array}$ & 932 & 2 & 62 & 1 & 911 & 8 & 10,2 & 5 \\
\hline De110\% a mais & 1.078 & 18 & 90 & 19 & 1.358 & 5 & 13,5 & 10 \\
\hline TOTAL & 1.063 & 20 & 89 & 20 & 841 & 20 & 10,6 & 20 \\
\hline
\end{tabular}

pauta alimentar dessas pessoas. De acordo com o que foi apresentado na Tabela 10, todas as famílias pesquisadas destinam sua produção prioritariamente para o consumo próprio. Também na Tabela 16 se observa a importância da produção da agricultura urbana no consumo de feijão, mandioca, verduras e algumas frutas. Assim, pode-se inferir que, entre as famílias pesquisadas, a agricultura urbana disponibiliza uma quantidade importante de alimentos fontes de nutrientes essenciais para a manutenção da saúde dos membros das famílias que a praticam.

Quanto aos sais minerais, tanto o cálcio quanto o ferro foram consumidos (em média) em quantidade inferior à preconizada, por uma parte das famílias integrantes da pesquisa. Ambos os minerais têm como principal fonte alimentos de origem animal (leite para o cálcio e as carnes para o ferro), os quais normalmente são de maior custo para a compra e de difícil produção no meio urbano, quando não proibido. Foi observado, por meio dos registros dos questionários, um consumo de frango maior que de carnes vermelhas entre as famílias, que normalmente optam pelos produtos com os menores preços no mercado.

Com esses dados, fica explícita a necessidade e a importância da agricultura urbana, pelo menos no que diz respeito às populações mais pobres. O consumo alimentar dessas famílias parece estar intimamente associado aos alimentos que produzem e à sua obtenção a um custo bem mais baixo do que se fossem adquiridos no mercado.

É necessário, entretanto, assinalar que estudos de maior profundidade, envolvendo maior número de integrantes na amostra e adoção de distintos métodos devem ser desenvolvidos com o intuito de melhor compreender o papel da agricultura urbana e a segurança alimentar.

\section{Conclusões}

A análise dos resultados apresentados neste trabalho permite algumas conclusões acerca da agricultura urbana no contexto estudado. Com relação à caracterização da população pesquisada, as evidências empíricas permitem afirmar que as famílias não são numerosas. Naquelas que praticam a agricultura urbana, não há predominância de sexo, de forma distinta do que se apresenta na literatura sobre o assunto. Os praticantes da agricultura urbana são predominantemente pessoas em idade adulta ou idosos. Além disso, os atores envolvidos na agricultura urbana são, na sua maioria, oriundos da zona rural, mas existe uma parcela não-desprezível de origem urbana. As ocupações econômicas exercidas pelos membros ativos das famílias de agricultores urbanos são precárias e de baixa qualificação, propiciandolhes rendimentos reduzidos. Todavia, vale destacar que menos de $1 / 4$ das famílias de agricultores urbanos estão abaixo da "linha de pobreza".

Em relação à prática da agricultura urbana, chama a atenção o fato de as produções serem obtidas praticamente sem o uso de insumos químicos e com a máxima utilização dos recursos disponíveis nos locais de produção. $\mathrm{O}$ uso reduzido de insumos modernos confere um caráter mais saudável aos alimentos produzidos. Cabe destacar também que a agricultura urbana é, na maioria dos casos, uma atividade que já possui uma certa tradição entre as famílias. Ela é exercida nos "quintais das residências". O destino dos 
produtos é predominantemente o autoconsumo, com muito pouco comércio. Neste sentido, a agricultura urbana pode ser considerada um modo de produção fora do mercado ou uma economia de subsistência.

As razões da prática da atividade resumem-se em consumo e subsistência, tradição na agricultura e lazer; no entanto a razão principal é a alimentação das famílias. As informações apresentadas sobre os tipos de produtos agrícolas obtidos reforçam essa idéia.

Entre as principais dificuldades enfrentadas pelas famílias pesquisadas estão a falta de dinheiro para investir na atividade, a falta de espaço físico e de conhecimento técnico. Aqui existe uma ampla possibilidade de intervenção em termos de políticas públicas.

Quanto à contribuição da agricultura urbana para a geração de renda, ela não cumpre necessariamente um papel de provedora de renda adicional, mas, dentro de suas características tradicionais de cultivo, permite às famílias uma economia importante por meio do consumo dos alimentos produzidos. Assim, ela complementa significativamente a alimentação das famílias.

A contribuição da agricultura urbana para a segurança alimentar e nutricional pode ser verificada nas análises dos resultados sobre o consumo de alimentos das famílias, em que ficou evidente que a preocupação atual não está no consumo de hortaliças, legumes e frutas, pois, graças à agricultura urbana, as famílias encontramse supridas dos nutrientes encontrados nesses produtos. Na verdade, para quem pratica agricultura urbana, faltam os alimentos mais ricos em minerais, como cálcio e ferro, que são encontrados no leite e derivados e nas carnes, respectivamente. Esses alimentos não são produzidos pelas famílias; por isso devem ser adquiridos no comércio por preços pouco acessíveis.

Para as famílias que integram o grupo pesquisado, para as quais a agricultura urbana é uma realidade, seriam interessantes políticas que promovam um acesso mais fácil a alimentos que não são produzidos e que são de difícil aquisição. Essas políticas poderiam promover o aumento da produção, visando à comercialização dos excedentes e permitir a geração de renda para aquisição dos alimentos não produzidos.

O aumento da produção é um fator desejado por muitas famílias pesquisadas; no entanto ainda estão ausentes as políticas públicas que promovam a disponibilidade de crédito às famílias mais pobres com o objetivo de estimular o aumento da produção. Muito poderia ser refletido sobre isso, principalmente porque a agricultura urbana abrange um amplo espectro de produtos e possui um caráter multifuncional, aspecto a ser considerado por todos aqueles que se preocupam com a questão da promoção de sistemas alimentares sustentáveis.

\section{Referências Bibliográficas}

Altieri MA et. al. The greening of the "barrios": urban agriculture for food security in Cuba. Netherlands. Agriculture and Human Values 1999; 16 : 131-40.

Avilla CJ \& Veenhuisen R. Aspectos econômicos da agricultura urbana [editorial]. In: La Revista Agricultura Urbana 2002 Ago.7. Disponível: http:/ www.ipes.org/aguila.Acesso em: 5 de jan. 2004.

Blanchemanche S., Marie CL, Mouriaux F., Peskine E. Multifonctionnalité de l'agriculture et status d'activité. Paris-France. Economie Rurale. 2000 nov.-déc.; 260:41-51.

Camarano AA \& Abramovay R. Êxodo rural, envelhecimento e masculinização no Brasil: panorama dos últimos 50 anos. Rio de Janeiro. IPEA; 1999. 23p. Texto para discussão n. 621.

COAG. Comitê de Agricultura. La agricultura urbana y periurbana. Organización de las Naciones Unidas para la Agricultura y la Alimentación - FAO. Roma: 25-29 jan. 1999. 60p.

Costa Beber C. Santa Maria, 200 anos: história da economia do município. Edição Comemorativa do Centenário da CACISM. Santa Maria: Cacism, 1998. 315p.

Dietary Reference Intakes - DRIs [ S. I.: s. n.], 2002. Disponível: http://www.nap.edu. Acesso em: 15 fev. 2006.

Drakakis-Smith D, Bowyer-Bower T, Tevera D. Urban poverty and urban agriculture: an overview of the linkages in Harare. Habitat International. Great Britain. v.19, n.2, p. 183-93. 1995. 
FAO. Select issues: urban agriculture: an oxymoron? In: The state of food and agriculture. Rome: FAO;1996. 29p.

Fleury A. \& Donadieu P. De l'agriculture périurbaine à l'agriculture urbaine. Le Revue Courrier de l'environnement. Paris, France, n.31, août. 1997. Disponível em: < http:/www.inra.fr/dpenv/ fleure31.htm>. Acesso em: 6 dez. 2003.

Frère N, Ludovico RMR, Martins PF da S. Agricultura urbana em Belém - Pará. In: Congresso Brasileiro de Economia e Sociologia Rural, 37, Anais... Foz do Iguaçu - PR. SOBER; 1999. p. 1-10.

Galeazzi MAM, Bonvino H, Lourenço FA, Vianna R. Inquérito de consumo familiar de alimentos: metodologia para identificação de famílias de risco alimentar. Cadernos de Debate. Campinas, v. IV. p.32-46. 1996.

IBGE. Censo Demográfico 2000. Disponível em: <http://www.ibge.org.br>. Acesso em 4 jan. 2004.

ILSI Brasil - International Life Sciences Institute do Brasil. SBAN - Sociedade Brasileira de Alimentação e Nutrição. Usos e Aplicações das "Dietary Reference Intakes”. São Paulo, nov. 2001. Disponível em <http:www.sban.com.br/educação/pesquisa/ dris.htm>. Acesso em: 20 mar. 2005.

Luna NM de M. Técnica dietética: pesos e medidas em alimentos. Editora Fundação Universidade Federal do Mato Grosso. Cuiabá, 1995.

Mattar FN. Pesquisa de marketing. São Paulo: Atlas. 1997, 4. ed. 273p.

Maxwell D, Levin C, Csete J. Does urban agriculture help prevent malnutrition? Evidence from Kampala. Food Police, Great Britain, v.23, n.5, p. 411-24. 1998.

National Research Council/Food and Nutrition Board. Recommended dietary allowances. $10^{\mathrm{a}} \mathrm{ed}$. Washington: National Academy Press, 1989. 284p.

Nugent R. Agricultura urbana e periurbana: segurança alimentar e nutrição. Texto inicial para discussão na conferência eletrônica promovida pela FAO, ETC, RUAF. 21 ago.-30 set. 2000. 7p.

Organización Mundial De La Salud. Necesidades de energía y de proteínas. Genebra: FAO/OMS/ONU, 1985. 220p. (Série de Informes Técnicos n. 724).

Pereira MT. Agricultura urbana e periurbana. Revista Qualidade de Vida, São Paulo, Ano 2, n.11, p.1-4, abr. 2000 .

Philippi ST, Szarfarc SC, Latterza AR. Virtual Nutri [programa de computador]. Versão 1.0 for windows. São Paulo: Departamento de Nutrição da Faculdade de Saúde Pública da Universidade de São Paulo (USP). 1996.

Projeto Institucional de Extensão: Núcleo da UFSM em Apoio à Rede de Solidariedade. Universidade Federal de Santa Maria. Pró- Reitoria de Extensão. Santa Maria. Abril de 2003.

Rocha S. Renda e pobreza: os impactos do Plano Real. Rio de Janeiro: IPEA. Texto para Discussão. n. 439, 1996.

Sachs I. Inclusão social pelo trabalho decente: oportunidades, obstáculos, políticas públicas. Estudos Avançados, São Paulo, v.18, n.51, p.23-49. 2004.

UNDP (United Nations Development Programme). Urban agriculture: food, jobs and sustainable cities. Publication Series for Habitat II. Volume One. New York, 1996. 300 p.

Yunus M. O banqueiro dos pobres. Editora Ática. 2000. 343p.

Zaluar A. A máquina e a revolta: as organizações populares e o significado da pobreza. 2.ed. São Paulo: Editora Brasiliense; 1994. p. 265.

Zeeuw H de, Gundel S, Waibel H. La integración de la Agricultura en las políticas urbanas. La Revista Agricultura Urbana. v.1, jul. 2000. Disponível em:< http:/www.ipes.org/aguila>. Acesso em: 21 out. 2003. 